\title{
A shortcut method with guided removal of degradation products and improved solvent performance for $\mathrm{CO} 2$ capture process
}

\author{
Hao Ling ${ }^{1}$, Sen Liu ${ }^{1}, J_{u a n} \mathrm{Lv}^{1}$, Yu Mao ${ }^{1}$, Hongxia Gao ${ }^{1}$, and Zhiwu Liang ${ }^{1}$ \\ ${ }^{1}$ Hunan University
}

November 4, 2020

\begin{abstract}
With the post-combustion $\mathrm{CO} 2$ capture process running for a long time, the degradation of aqueous amine-based is inevitable. Unfortunately, a simple and effective way to increase the economic feasibility of $\mathrm{CO} 2$ capture process after accumulated degradation products remains absent, and little attention has been paid to the real effect of degradation products on the CO2 capture performance in aqueous amine solutions. We propose a simple experimental and computational method that can evaluate the performance and regeneration energy of solvent after change. The method can determine key degradation products that affecting the performance of solvent, so as to guide the selective removal of degradation products and improve solvent performance.
\end{abstract}

\section{Hosted file}

manuscript.pdf available at https://authorea.com/users/372878/articles/490735-a-shortcutmethod-with-guided-removal-of-degradation-products-and-improved-solvent-performance-forco2-capture-process 